\title{
Calcifying Epithelioma of Malherbe: A Rare Tumor in Unusual Location
}

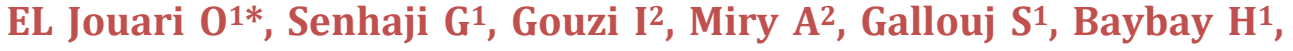 \\ Hammas $\mathrm{N}^{2}$ and Mernissi FZ ${ }^{1}$ \\ ${ }^{1}$ Department of Dermatology, University Hospital Hassan II Fez, Morocco \\ ${ }^{2}$ Department of Anatomopatology, CHU University Hospital Hassan II Fez, Morocco
}

*Corresponding author: Ouiame El Jouari, Department of Dermatology and

\section{Case Report}

Volume 3 Issue 3

Received Date: September 28, 2018

Published Date: November 05, 2018

DOI: $10.23880 /$ cdoaj- 16000156

Venereology, University Hospital Hassan II Fez, Morocco, Tel: 00212645768798; Email: eljouariouiame@gmail.com

\section{Abstract}

Calcifying Epithelioma of Malherbe also known as pilomatrixoma or pilomatricoma, is a benign skin neoplasm that originates from the hair follicle matrix cells. It occurs most commonly in head and neck area. Because of the low incidence and variable clinical presentation, pilomatricoma is a tumor commonly misdiagnosed and histopathologicaly confirmed. Complete surgical excision is mandatory to avoid recurrence. We aim to report a case of this rare tumor arising in a very unusual location.

Keywords: Nodule; Malleolus; Calcifying epithelioma of Malherbe; Pilomatricoma

\section{Introduction}

Calcifying epithelioma of Malherbe (pilomatricoma) is a rare benign neoplasm of hair matrix cell origin [1]. It can occur at any age; congenital forms have been reported. It affects women particularly with a sex ratio of 1.5 [2].The usual locations are the neck and the head [3]. Since it is not commonly suspected preoperatively, certain distinctive clinical features of tumor should suggest clinical diagnosis followed by histopathologic confirmation [4]. We present a rare case of pilomatricoma in an exceptional location.

\section{Case Report}

A 54-year-old woman presented with 3 years' history of a painful tumefaction of the external malleolus of the right foot. On examination a $2 \mathrm{~cm}$ nodule, hard, adherent to the skin but mobile from the deep plane. The skin was normal without any inflammatory signs (Figure 1). No palpable lymphadenopathy was identified. Dermoscopy of the lesion showed yellowish area with an erythematous background (Figure 2). A total surgical excision of the tumor, under local anesthesia, was performed. Histological examination revealed a deep epithelial proliferation mummified cells with a very pale eosinophilic aspect, without having seen any nuclei. Presence of a structureless eosinophilic cells lacking nuclei called shadow cells associated to giganto-cellular granulomatous reaction with a foreign body and some calcifications (Figures $3 \& 4$ ). All these findings were suggestive of Mummified Epithelioma of Malherbe. At follow-up visits, no recurrence was noted with a decline of 24 months. 

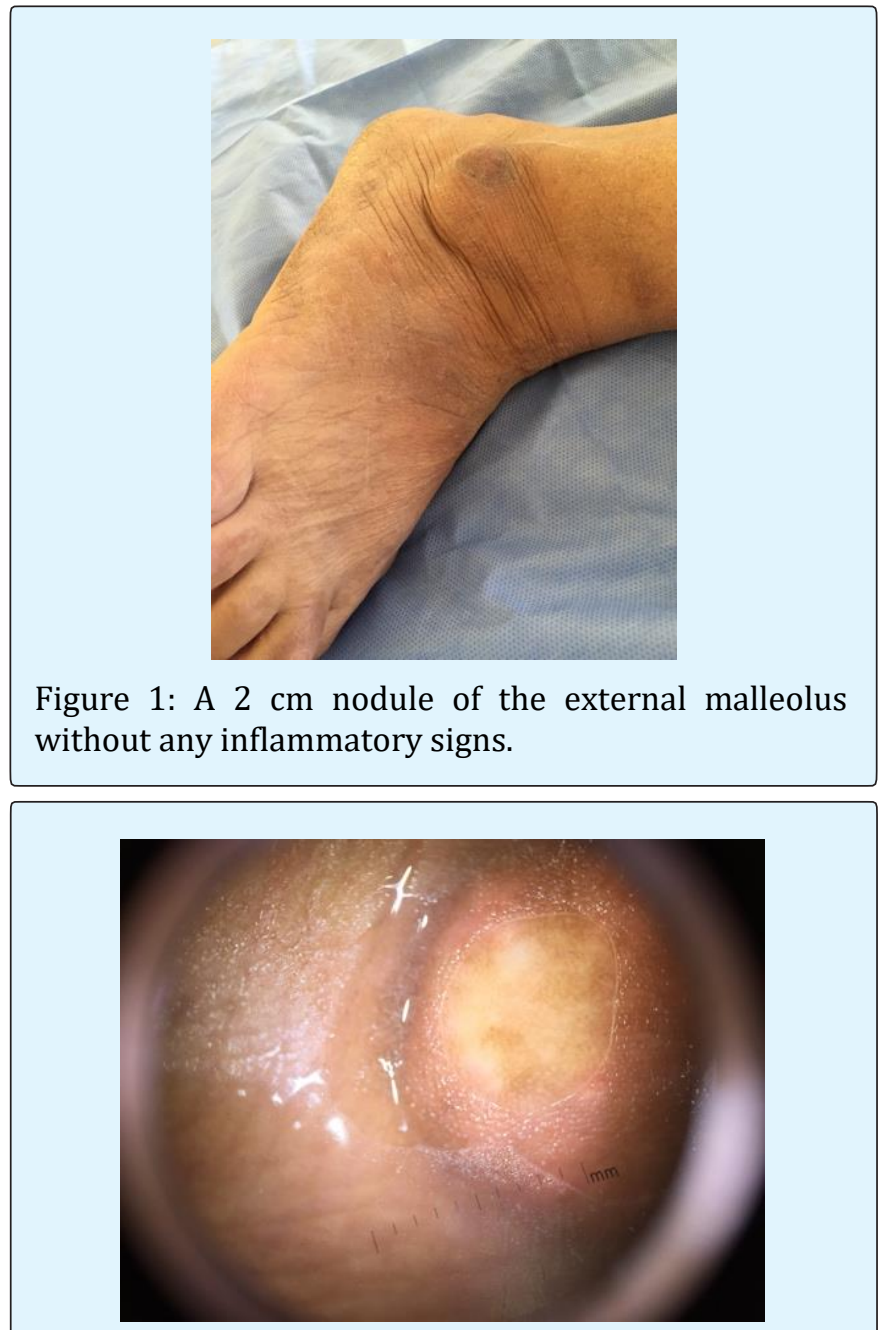

Figure 2: Dermoscopy showing yellowish area with an erythematous background.

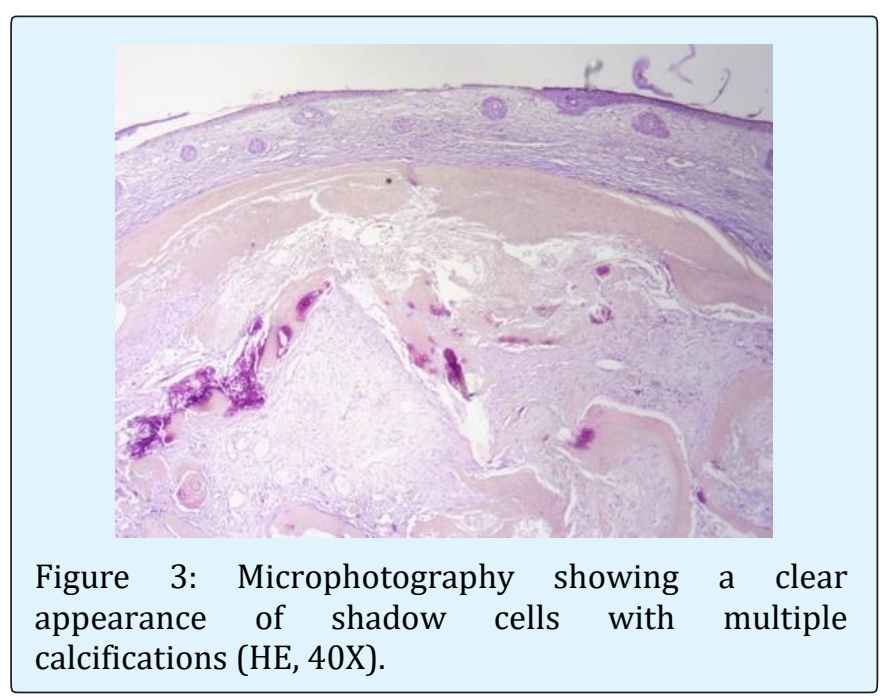

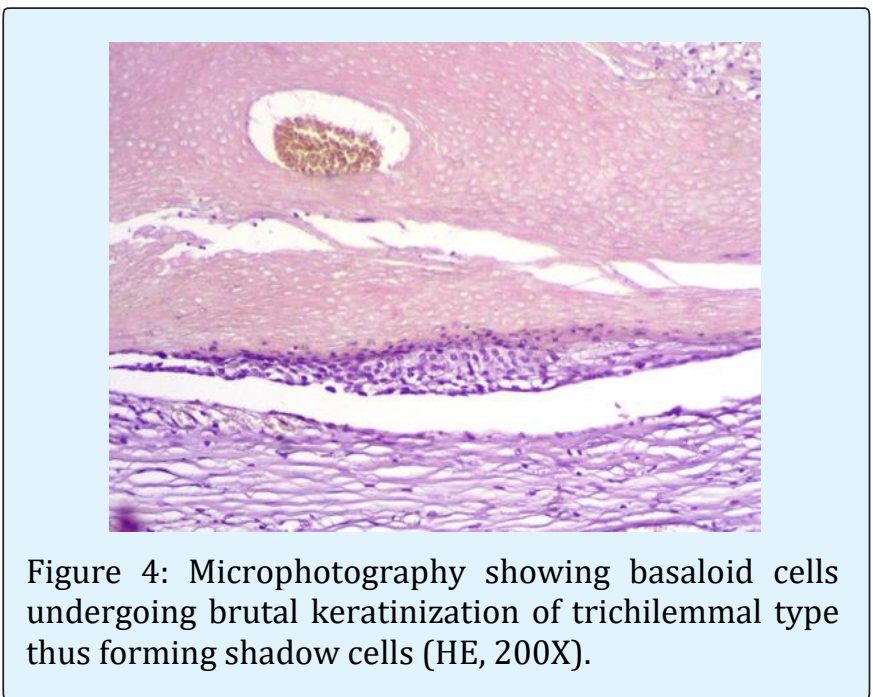

\section{Discussion}

Calcifying epithelioma of Malherbe, also known as pilomatrixoma or pilomatricoma, is a benign skin neoplasm that originates from the hair follicle matrix cells [5]. Pilomatricoma typically presents as a firm, slowgrowing, subcutaneous mass that is well circumscribed with a general size $<3 \mathrm{~cm}$ in diameter [6]. It occurs most commonly in head and neck areas, especially cervical, frontal and temporal regions, eyelids and preauricular regions; although the upper extremities, trunk and lower extremities can be affected, in decreasing order of frequency [1]. Dermoscopic features of pilomatricoma reported in the literature are yellowish-white structures together with streaks, linear irregular vessels and hairpin like vessels [7,8]. Because of the low incidence and variable clinical presentation, pilomatricoma is a tumor commonly misdiagnosed [5]. The presentation of these subcutaneous nodules may resemble benign lesions such as a sebaceous adenoma, keratoacanthoma, ossifying hematoma, and fibroxanthoma, or malignant lesions such as squamous cell carcinoma [9]. Radiologic imaging is of little diagnostic value apart from ultra- sonography that demonstrates the superficial position, the continuity of the lesion with deeper structures and the degree of calcification [6]. The only truly reliable means of diagnosis remains pathological evaluation [9]. Histopathologic examination reveals the tumor to be grossly well circumscribed and firm to gritty in consistency. Microscopic examination shows numerous islands of epithelial cells with characteristic arrangement of basophilic cells in the periphery and shadow cells in the center. As the tumor matures the number of basophilic cells looses their nuclei and becomes shadow cells. 


\section{Clinical Dermatology Open Access Journal}

Calcification is seen in $75 \%$ of the cases. A sheet of intensely eosinophilic keratinous material is seen within necrotic areas, and this may induce a foreign body giant cell reaction [4].

Surgical excision of this tumor is a sufficient and curative treatment, with excellent postoperative prognosis for both cosmesis [9] and to prevent the rare possibility of malignant transformation into pilomatrix carcinoma [4]. The prognosis of the pilomatricoma is good [10].

\section{Conclusion}

We report the case of a pilomatricoma in the unusual location of the malleolus. In order to help clinicians to better diagnose this entity.

\section{References}

1. Upile T, Jerjes W, Sipaul F, Sandison A, Kafas P, et al. (2012) A patient with ulcerated calcifying epithelioma of Malherbe in the pinna: case report. Head \& Neck Oncology 4: 25.

2. Nasreddine FZ, Hali F, Chiheb S (2016) Pilomatricoma: a study of 22 cases. Pan Afr Med J 23: 254.

3. Yoshimura Y, Obara S, Mikami T, Matsuda S (1997) Calcifying epithelioma (pilo- matrixoma) of the head and neck: analysis of 37 cases. Br J Oral Maxillofac Surg 35(6): 429-432.
4. Javed Ali M, Honavar DG (2011) Malherbe's Calcifying Epithelioma (Pilomatrixoma): An Uncommon Periocular Tumor. Int J Trichology 3(1): 31-33.

5. Fernandes BF, Al-Hinai A, Belfort RN, Castiglione E, Arthurs B, et al. (2008) Anetodermic Variant of a Periorbital Pilomatricoma. Ophthal Plast Reconstr Surg 24(5): 419-421.

6. Papadavid E, Mistidou M, Katoulis A, Zambacos G, Stavrianeas N, et al. (2010) Familial occurrence of calcifying epithelioma of Malherbe. Int J Dermatol 49(12): 1456-1457.

7. Zaballos P, Llambrich A, Puig S, Malvehy J (2008) Dermoscopic findings of pilomatricomas. Dermatology 217: 225-230.

8. Ayhan E, Ertugay O, Gundogdu R (2014) Three Different Dermoscopic View of Three New Cases with Pilomatrixoma. Int J Trichology 6(1): 21-22.

9. De Rosa DC, Hurtubise KL (2012) Pilomatricoma: An Unusual Dermatologic Neoplasm. Hawaii J Med Public Health 71(10): 282-286.

10. Marback EF, Cardoso C, Moitinho LM, Marback RL (2007) Clinicopathologic study of eyelid pilomatrixoma: the experience of the "Hospital Universitario Prof. Edgard Santos. Arq Bras Oftalmol 70: 501-503. 